\title{
Polymorphic microsatellite loci for Japanese Spanish mackerel (Scomberomorus niphonius)
}

\author{
L. Lin ${ }^{1,2}$, L. Zhu' ${ }^{2}$, S.-F. Liu ${ }^{2}$, Q.-S. Tang ${ }^{2}$, Y.-Q. Su ${ }^{1}$ and Z.-M. Zhuang'* \\ ${ }^{1}$ College of Oceanography and Environmental Science, \\ Xiamen University, Xiamen, China \\ ${ }^{2}$ Key Laboratory for Fishery Resources and Eco-Environment, \\ Shandong Province, Yellow Sea Fisheries Research Institute, \\ Chinese Academy of Fishery Sciences, Qingdao, China \\ Corresponding author: Z.-M. Zhuang \\ E-mail: zhuangzm@ysfri.ac.cn
}

Genet. Mol. Res. 11 (2): 1205-1208 (2012)

Received August 9, 2011

Accepted December 13, 2011

Published May 8, 2012

DOI http://dx.doi.org/10.4238/2012.May.8.2

\begin{abstract}
We isolated and characterized 21 polymorphic microsatellite loci in Japanese Spanish mackerel (Scomberomorus niphonius) using a (GT) ${ }_{13}$-enriched genomic library. Forty individuals were collected from Qingdao, China. We found 3 to 24 alleles per locus, with a mean of 8.8. The observed and expected heterozygosities ranged from 0.263 to 0.975 and from 0.385 to 0.946 , with means of 0.655 and 0.685, respectively. Deviation from Hardy-Weinberg proportions was detected at three loci. Two loci showed evidence for null alleles. These microsatellite markers will be useful for population genetic analysis of Japanese Spanish mackerel.
\end{abstract}

Key words: Scomberomorus niphonius; Japanese Spanish mackerel; Microsatellite loci; Population structure 


\section{INTRODUCTION}

Japanese Spanish mackerel (Scomberomorus niphonius), a pelagic fish widely distributed in subtropical and temperate waters of the northwest Pacific (Shui et al., 2008), is one of the important catch targets in China's fishery industry. Recent two-decade cruise data indicate that biological characteristics related to the population structure of the S. niphonius, such as the mean age, length and the age at sexual maturity, had obviously changed (Jin et al., 2006). The changes were mostly due to overexploitation and environmental changes (Jin et al., 2006). The protection and sustainable utilization of Japanese Spanish mackerel resources in China's coastal waters have drawn the attention of relevant authorities. Analysis of the population structure of S. niphonius may provide new perspectives on population assessment and efficient management in the $S$. niphonius resources.

Characterized by hypervariability, abundance, neutrality, codominance, and unambiguous scoring of alleles, microsatellite markers are referred as to the finest identification of population structure in marine fishes, among molecular markers (Tautz, 1989; Zhan et al., 2009). In S. niphonius, 18 polymorphic microsatellite loci were isolated (Yokoyama et al., 2006; Xing et al., 2009). Here, we describe the development of an additional 21 loci that will increase the power available for detecting fine-scale population genetic structure and gene flow of $S$. niphonius.

\section{MATERIAL AND METHODS}

Forty individuals were collected from Qingdao, China. Samples were preserved at $-20^{\circ} \mathrm{C}$ until DNA extraction. A dinucleotide-enriched genomic library was constructed following the method of Ma and Chen (2009). In brief, genomic DNA was extracted from muscle tissue and digested with $M s e$ I restriction enzyme (New England Biolabs, USA). The DNA fragments were ligated to the adapters (5'-TAC TCA GGA CTC AT-3'/5'-GAC GAT GAG TCC TGA G-3'). The ligated products were then pre-amplified in a $25-\mu \mathrm{L}$ reaction system using the adapter specific primer 5'-GAT GAG TCC TGA GTA A-3' to verify successful ligation and increase DNA concentration. The biotin-labeled probe $(\mathrm{GT})_{13}$ was applied to hybridize with the products from pre-amplification. Subsequently, the hybrids were captured by the streptavidincoated magnetic beads (Promega, USA), and the DNA fragments obtained and eluted from the magnetic beads were amplified by the adapter specific primer. The final amplification products were ligated into the pMD18-T vector (TaKaRa, Japan) and transformed into Escherichia coli DH5 $\alpha$ competent cells. The positive clones were randomly sequenced with an ABI Prism 3730 automated DNA sequencer (Applied Biosystems, USA). Microsatellite repeats were found in 92 of the sequenced clones. PCR primer pairs were designed to amplify 72 microsatellite loci with suitable flanking regions using the PRIMER PREMIER 5 software (Premier Biosoft International, USA).

The designed primers were evaluated using 40 individuals of $S$. niphonius. PCR was performed on a Veriti Thermal Cycler (Applied Biosystems) in a total volume of $25 \mu \mathrm{L}$ containing $0.4 \mu \mathrm{M}$ of each primer, $0.2 \mathrm{mM}$ of each dNTP, 1 X PCR buffer, $2 \mathrm{mM} \mathrm{MgCl}, 1 \mathrm{U}$ Taq polymerase (Fermentas, USA) and 10-100 ng DNA. The PCR cycling profile consisted of one cycle at $94^{\circ} \mathrm{C}$ for $5 \mathrm{~min}, 35$ cycles of $45 \mathrm{~s}$ at $94^{\circ} \mathrm{C}, 1 \mathrm{~min}$ at the locus-specific annealing temperature (Table 1), and $45 \mathrm{~s}$ at $72^{\circ} \mathrm{C}$, and a final cycle of $10 \mathrm{~min}$ at $72^{\circ} \mathrm{C}$. The PCR products were 


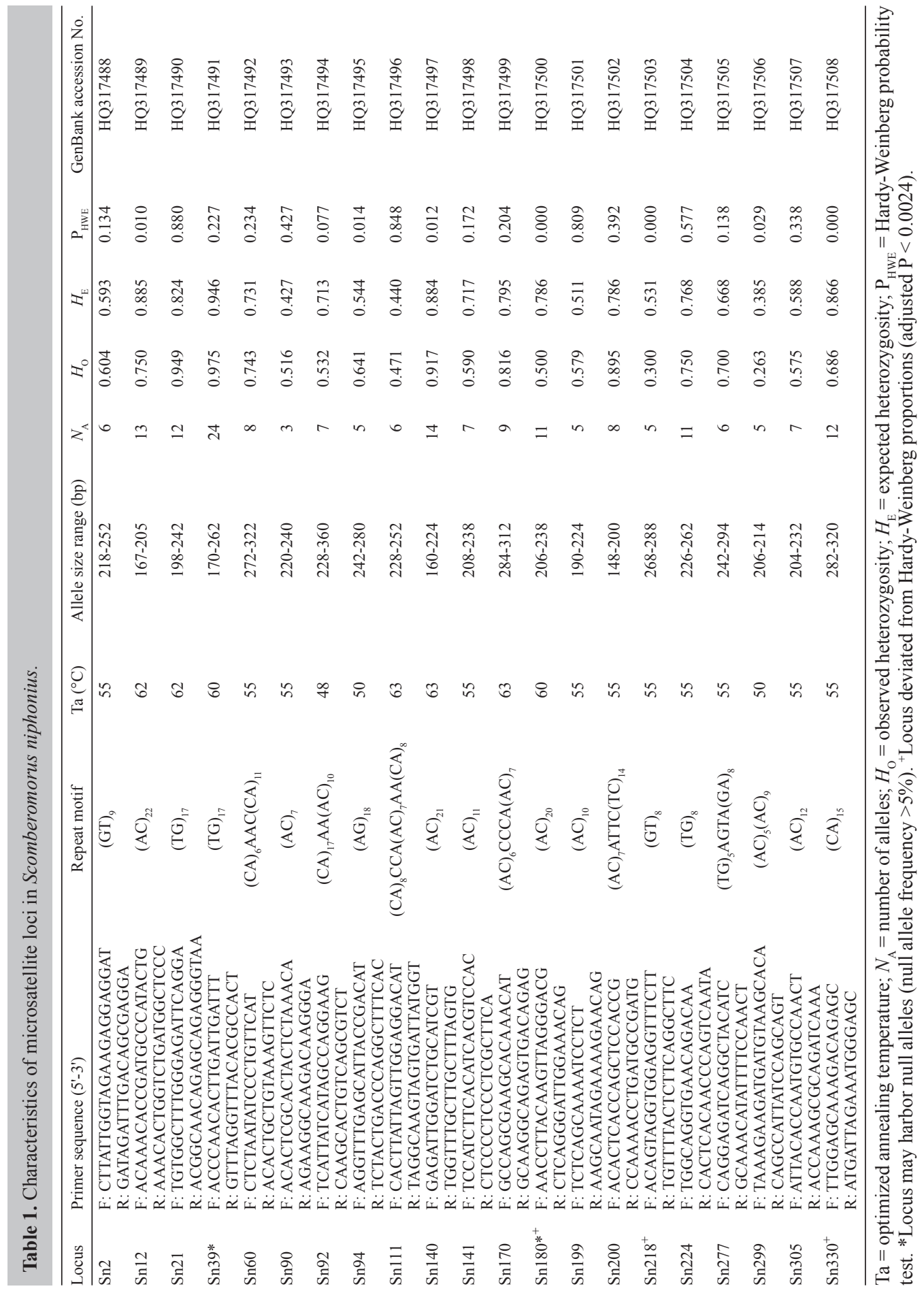


separated on a $6 \%$ denaturing polyacrylamide gel, and visualized by silver staining. Allele size was estimated according to the pBR322/MspI marker (TianGen, China). The observed and expected heterozygosities together with tests for Hardy-Weinberg equilibrium and linkage disequilibrium were determined by GENEPOP 4.0 (Rousset, 2007). Null allele frequencies (Brookfield, 1996) were calculated by MICRO-CHECKER 2.2.3 (Van Oosterhout et al., 2004). All results for multiple tests were corrected using Bonferroni's correction (Rice, 1989).

\section{RESULTS AND DISCUSSION}

A total of 21 of 72 loci were cleanly amplified and shown to be polymorphic. The number of alleles per locus ranged from 3 to 24 with an average of 8.8 (Table 1). The observed and expected heterozygosities ranged from 0.263 to 0.975 and from 0.385 to 0.946 , with averages of 0.655 and 0.685 , respectively (Table 1). No loci showed significant deviation from Hardy-Weinberg proportions except for loci Sn180, Sn218 and Sn330. Two loci (Sn39 and Sn180) showed evidence of null alleles (null allele frequency $>5 \%$ ). No significant gametic disequilibrium was detected between locus pairs.

\section{ACKNOWLEDGMENTS}

Research supported by the National Natural Science Foundation of China (grant \#40776097 and \#31061160187) and the National High Technology Research and Development Program of China (grant \#2009AA09Z401).

\section{REFERENCES}

Brookfield JF (1996). A simple new method for estimating null allele frequency from heterozygote deficiency. Mol. Ecol. 5: 453-455.

Jin XS, Cheng JS, Qiu SY, Li PJ, et al. (2006). Resource Dynamic of Important Fishery Species. In: Comprehensive Investigation and Assessment of Fishery Resources in Yellow Sea and Bohai Sea (Chen HC, ed.). Ocean Press, Beijing, 195-204.

Ma HY and Chen SL (2009). Isolation and characterization of 31 polymorphic microsatellite markers in barfin flounder (Verasper moseri) and the cross-species amplification in spotted halibut (Verasper variegatus). Conserv. Genet. 10: 1591-1595.

Rice WR (1989). Analyzing tables of statistical tests. Evolution 43: 223-225.

Rousset F (2007). GENEPOP'007: a complete reimplementation of the GENEPOP software for Windows and Linux. Mol. Ecol. Notes 8: 103-106.

Shui BN, Han ZQ, Gao TX and Miao ZQ (2008). Genetic structure of Japanese Spanish mackerel (Scomberomorus niphonius) in the East China Sea and Yellow Sea inferred from AFLP data. Afr. J. Biotechnol. 7: 3860-3865.

Tautz D (1989). Hypervariability of simple sequences as a general source for polymorphic DNA markers. Nucleic Acids Res. 17: 6463-6471.

Van Oosterhout C, Hutchinson WF and Wills DPM (2004). MICRO-CHECKER: software for identifying and correcting genotyping errors in microsatellite data. Mol. Ecol. Notes 4: 535-538.

Xing SC, Xu GB, Liao XL, Yang GP, et al. (2009). Twelve polymorphic microsatellite loci from a dinucleotide-enriched genomic library of Japanese Spanish mackerel (Scomberomorus niphonius). Conserv. Genet. 10: 1167-1169.

Yokoyama E, Sakamoto T, Sugaya T and Kitada S (2006). Six polymorphic microsatellite loci in the Japanese Spanish mackerel, Scomberomorus niphonius. Mol. Ecol. Notes 6: 323-324.

Zhan A, Hu J, Hu X, Zhou Z, et al. (2009). Fine-scale population genetic structure of Zhikong scallop (Chlamys farreri): do local marine currents drive geographical differentiation? Mar. Biotechnol. 11: 223-235. 